Este artigo faz uma discussão sobre as posiçōes ocupadas pelos membros familiares na modernidade, bem como reavalia suas funçōes diante da tarefa educativa. A análise procurou valer-se de conceitos teóricos da psicanálise, para pensar a família e a educação nos dias de hoje. Considerando a família a primeira instituição responsável pela organização subje tiva que viabiliza a inserção dos sujēitos na cultura, quais seriam as reflexões necessárias para a sua compreensão em face da evidencia de que a família mudou? Quais os paradoxos que estabelecem as possibilidades e impossibilidades no ato de educar? A proposta é suscitar questionamentos sobre a familia e a educação modernas, sem o objetivo de oferecer uma metodologia ou um receituário para o bem-educar.

Familia; modernidade; educação familiar

FATHER, MOTHER AND SON - REFLECTIONS ON EDUCATION IN MODERNITY

This article promotes a discussion about the position of the members of the family nowadays, as well as re-evaluates their roles facing the educational task. We tried to take into regard theorical concepts of Psychoanalysis in order to think about family and education nowadays. Considering the family as the first institution in charge of the subjective organisation which makes possible to put the subjects and culture together, what would be necessary to make them understand that the concept of family has changed? What is really feasible when we think about education? This paper intends to be thought-provoking, highlighting the roles of modern family and education, but without offering a methodology or a prescription for what a good education must be. Family; modernity; family education

\section{PAI, MÃE E FILHO - REFLEXÕES SOBRE FAMÍLIA E EDUCAÇÃO NA MODERNIDADE}

Cláudia Valéria Furtado de Oliveira Araújo
MY

ão podemos, no início de outro milênio, escrever sobre um conceito único de família principalmente tomando na devida conta a diversidade e a dificuldade dos teóricos em defini-la. Pensar no sentimento de família ${ }^{1}$ é antes de mais nada deparar com o imaginário acerca desta instituição: lugar do amor, da unidade, da solidariedade entre as pessoas com laços afetivos e/ou consangüíneos. Visão romanceada, que tem na história uma possibilidade de compreensão da formação desse imaginário cristalizado.

Entre os séculos XVI e XVIII, as classes privilegiadas, distanciando-se das preocupações com o pa-

- Psicóloga escolar e clínica, especialista em infância pela Escola e Clínica Psicanalítica do Ceará, e mestranda do Programa de Pós-Graduação em Educação Brasileira da Universidade Federal do Ceará. 
trimônio, a honra e o nome, desenvolvem forte sentimento em torno da família formada por pai, mãe e filho, concomitantemente ao sentimento de infância. É também nesse momento que aparecem os desejos de privacidade e intimidade, fenômeno primordialmente burguês. Com a ajuda da Igreja, a família adquiriu, finalmente, seu lugar sagrado, ao instituir com o casamento a família conjugal conforme a conhecemos. Ao lado da história romântica, em contraposição, é nas páginas policiais e noticiários sobre a violência doméstica que encontramos o seu reverso.

As mudanças que aconteceram, principalmente nos últimos 20 anos, como o aumento dos divórcios nas sociedades industrializadas, o maior poder econômico do casal que trabalha fora, o aumento da escolaridade, o surgimento de possibilidades religiosas para além do catolicismo ortodoxo, guardam íntima relação com os modelos atuais de família: menos tradicionais (idealizados), conseqüentemente mais humanizados.

Inegavelmente, estamos diante de uma realidade que os apelos da modernidade fizeram constituir. Em face disso, a subjetividade reorganiza-se de modo que, pelo menos, possa se tentar dar conta do real, estabelecendo elementos estruturantes com o presente.

Sem dúvida alguma, é na família que o ingresso na cultura ocorre em primeira instância. E, em família, é na relação com as figuras parentais que a criança é habilitada a se constituir como sujeito diante de outros sujeitos por meio da identificação materna, da alienação nas instâncias ideais, da intervenção paterna, da ascensão à linguagem. Daí em diante, o resultado em maior ou menor grau de sucesso no sentido de um viver saudável ou viver criativo ${ }^{2}$ dependerá da configuração que se elaborou desde quando o sujeito começou a fazer parte de sua teia familiar.

Cada família tem organização própria. E podemos imaginar essa organização como uma teia de aranha, tanto no que ela significa de perfeição arquitetônica quanto no que ela nos leva a associar: "lugar de armadilha", onde se fica enredado. Na trama dos fios, qualquer mínimo movimento é percebido e implica uma reverberação em todo o sistema.

Falar sobre o lugar do filho implica pressupor os lugares de pai e mãe, e vice-versa. Falar do lugar de mãe implica que antes ela também foi filha para uma outra mãe, e assim por diante. Sempre levando em conta ainda que estas relações são mediadas pelo universo comunicacional, portanto, estando imersas na cultura, onde não poderão ser analisadas de modo isolado.

A noção de antecessor e sucessor, trabalhada na aprendizagem de conteúdos matemáticos, pode ser de grande ajuda para a compreensão dessa articulação. Para entendermos a noção de quantida- 
de do número é preciso remetê-lo à cadeia numérica a que ele pertence, sendo por ela significado. Na família, para situarmos a história de seus membros, faz-se necessário observarmos as vinculações existentes entre eles. Ressaltando que estes sujeitos estão envoltos em um universo de comunicação em que, pela linguagem, as trocas são possibilitadas.

O fato de que tudo isso está inserido na cultura, com as características modernas de economia global, de final de milênio, de avanço tecnológico, de disparidades sociais, de nova concepção de tempo e de mudanças nas instituições sociais (família, escola, Igreja, Estado etc.), leva-nos a acreditar que na complexidade podemos encontrar acesso ao que estamos buscando. Toda simplificação termina por destituir a família de elementos vitais ao seu funcionamento.

Os valores, os mitos, os segredos, os preconceitos, todos estes temas vão compondo a textura familiar, no contexto da qual cada um vai significar o seu espaço, articulando as demandas de forma mais ou menos simbólica, imaginária ou até atuando em manifestações patológicas (que é a maneira dolorosa de realizar um espaço de vida).

\section{PENSANDO EM FAMÍLIA(S)}

Família... adultos... criança... educação! Uma cadeia associativa inevitável. Educar crianças é o projeto social por excelência, delegado aos pais, responsáveis pela transmissão da cultura.

"Entre todos os grupos humanos, a família desempenha um papel primordial na transmissão da cultura. Se as tradições espirituais, a manutenção dos ritos e dos costumes, a conservação das técnicas e do patrimônio são com ela disputados por outros grupos sociais, a família prevalece na primeira educação, na repressão dos instintos, na aquisição da língua acertadamente chamada materna” (Lacan, 1987, p. 13).

Assim é que, de uma geração para outra, asseguramos também alianças psíquicas que promovem outra hereditariedade, ao fazerem circular emoções de forma organizada e estabelecerem estruturas de comportamento social que constroem o aparato subjetivo.

Educamos para garantir uma continuidade? Afinal, para que educamos nossas crianças? De imediato, qual seria a resposta moderna para esta pergunta aparentemente banal?

A finalidade de educar varia cultural e historicamente. Quem demonstrou detalhadamente esta mudança foi Ariès (1981), situando a infância como uma construção dos dois últimos séculos. No 
Antigo Regime, educava-se para garantir a descendência e a tradição.

$\mathrm{Na}$ modernidade, a infância é vislumbrada como um tempo separado da vida adulta, quando o amor parental protege e encaminha para a felicidade mítica, a qual aponta para a esperança em um futuro promissor de duas maneiras: 1) por meio dos ideais imaginários garantir às crianças (cada qual com a "sua", já que numa sociedade individualista será amada aquela com a qual estabelecemos laços identificatórios narcisistas) a felicidade e a evitação da dor "Meu filho não irá passar pelo que eu passei”; 2) ou educando as crianças para que elas possam realizar-se em um projeto de vida próprio, atravessando o campo idealizado pelos pais, para que os filhos sejam livres sem, no entanto, deixarem de estar implicados em um projeto que existiu antes de nascerem.

Diferentemente dos animais inferiores, que não possuem linguagem nem aparato subjetivo de acesso ao simbólico, precisamos aprender a agir humanamente. Para o reino animal, a natureza estabelece pelo instinto um modo de fazer, uma cunhagem biologicamente herdada, que se encarrega de transmitir um padrão que define previsivelmente a ação. Neste caso, podemos dizer que estamos tratando de fato de um comportamento que pode ser observado ao longo do tempo e determinado em função da sobrevivência e da reprodução.

É possível conferir essa diferença entre o homem e o animal em simples observação dos filhotes de ambos. Para o primeiro, um longo período será necessário até que este esteja apto a enfrentar por si os desafios de viver independente de um outro. Nenhum descendente é tão pouco equipado, tão desamparado, tão necessitado de que seja "adotado" para estabelecer sua condição quanto o bebê humano.

A tarefa de ser "ensinante" $e^{2}$ conferida primeiramente aos núcleos familiares, que não significam como norma o modelo triangular papai, mamãe e filhinho. Mas não é sempre que coincidem família biológica e laços consangüíneos.

Os padrões familiares tornam-se tão diversos quanto possa apontar o curso do desejo... Enfim, possuímos um modelo hoje? Homem casado com segunda esposa, existindo filhos de dois relacionamentos; mãe solteira convivendo com os pais, o filho tendo no avô o referencial paterno; mãe separada morando com o filho mais novo, enquanto o pai mora com o mais velho (junto à atual namorada, que também já tem filhos de um relacionamento anterior); casal que mora junto, mas que está separado, ambos mantendo relações extraconjugais que são do conhecimento dos filhos; casal homossexual, em que um dos pares fez operação do órgão genital, havendo "adotado" uma criança etc. A mãe não é necessariamente quem pariu, o pai não é obrigatoriamente quem fecundou principalmente nos tempos atuais, quando os médicos fertilizam artificialmente... E o filho? Bem, este terá de se vincular ao que o antecede.

Entretanto, se há uma quebra, há uma continuidade também: os lugares fundamentais familiares ainda 
são invariavelmente os mesmos: instância materna, instância paterna, que estabelecem a posição da filiação (sem que aqui seja necessário exame algum de consangüinidade ou DNA). A referência à mãe como função (e não como mulher que biologicamente pariu) e ao pai também como função (e não ao homem que fisiologicamente fecundou) subverte a compreensão moralista de família. A noção de função instaura uma independência em relação à pessoa. A tarefa da "mãe" será possibilitar ao sujeito (filho) realizar a passagem "de um puro pedacinho de carne com boca e olhos" (Cabas, 1982, p. 117) a uma forma erógena, logo, humana. Ao "pai" compete interditar o acesso do filho à mãe, servindo para ambos como barra a ilusão de completude.

Enquanto a "mãe" constrói, codifica e dá nome às necessidades da sua criança, viabilizando a identificação necessária a sua estruturação como ser, o "pai" manifesta-se realizando uma interdição com efeito duplo (para a criança e para a mãe) ao encarnar a $l e i^{4} \mathrm{e}$ ao submeter-se a ela pela ordem da cultura.

Desde a origem da organização social humana, existem investimentos amorosos, interdições e leis, representadas nos núcleos familiares pelas pessoas que ocupam estas funções para as novas gerações. As diferenças da modernidade marcam que novos acordos entre as funções subjetivas ocupadas pelos membros familiares estão se estabelecendo de modo mais ou menos impregnante.

Homens e mulheres em uma infinita combinação de probabilidades confirmam: mudamos e construímos diversidades na forma de viver. E, com maior nitidez do que antes, é possível observar também que os papéis sociais não coincidem, ponto a ponto, mulher e feminino, homem e masculino. O sexo é definido anatomicamente após o nascimento, e a sexualidade é uma construção posterior, que se inicia na família. As primeiras investigações da criança são sempre de natureza sexual. Ela tem necessidade de definir o seu lugar no mundo. A princípio, observa as diferenças sexuais e situa seus questionamentos em relação aos pais, ao que eles esperam que ela seja: "Qual é a minha origem em relação ao desejo de vocês? Por que me puseram no mundo, para atender a quais expectativas e esperando que eu me torne o quê?" (Kupfer, 1997, p. 81).

Não havendo mais modelos a seguir e diante de tantas diferenças, como os filhos estabelecem uma subjetividade própria? Constituem a sexualidade em referência a que instâncias familiares? Dispensa-se a organização tradicional para substituí-la pelo quê?

\section{EDUCAÇÃO FAMILIAR: VÍNCULO PARADOXAL}

Melman comenta que guardamos uma relação de natureza paradoxal com a educação que recebemos (Jerusalinsky et al., 1994). Por um lado, por devermos tudo o que somos a ela, a adoramos. Por outro, ao justificar nossos males com base na educação que tivemos, 
a odiamos. Assim, todo o olhar sobre a educação só pode ser pensado a partir dessa ambigüidade em relação ao nosso núcleo familiar.

Também nos posicionamos de modo paradoxal em relação à própria convivência em sociedade, já que é em função desta que nos vemos obrigados a abdicar dos nossos desejos para nos inscrever em um grupo social. Tanto a família quanto os demais grupos sociais nos lançarão em lugares identificadores que, numa primeira instância, contribuirão para a nossa organização pulsional: "Uma vida sob o inteiro domínio (...) das pulsões seria impossível e até mesmo mortal" (Kupfer, 1997, p. 37).

Um complicador à educaçào na modernidade é o fato de que o simulacro tornou-se a base da construção da realidade. Antes acreditávamos em educar para a construção de um sujeito valoroso, cujo reconhecimento social adviria como conseqüência natural de sua posição reta e talentos realizados pelos seus esforços e o suor de seu trabalho. Hoje é difícil confrontar-se com um real que mostra o oposto. Não basta ser, é preciso parecer ser. Toda a estratégia de jogos instantâneos de imagens "antes e depois" veiculados através de alguns meios de comunicação indicam um caminho de "Você decide": ser um, mais um, a somar-se aos milhares para confrontar o perde-ganha da ética moderna. A maioria comanda e decide, sem poupar a tradição, os valores, unificando imaginariamente ideais... A vox populi tem uniformizado mais do que diferenciado, provocado pouca reflexão, globalizado muito mais do que particularizado o ser humano.

A atualidade também aventa uma preocupação relativa à convivência harmônica em sociedade. E tanto não é natural que saibamos a priori o que é ser cidadão convivendo em harmonia, que necessitamos ser educados para isso. Que a família se preocupe, que a escola se inquiete, parece natural, já que são instâncias formadoras por princípio.

Em situação familiar, são amadas as crianças que melhor espelham, imaginariamente, as figuras que funcionam para elas como pais.

Em situação escolar, são muito bem-vistos os alunos que reproduzem todo o conhecimento supostamente ensinado pelo professor em sala de aula. Quanto mais parecido um aluno se torne ao seu professor, tanto mais será apreciado.

Em ambas as situações, a cena especular parece ser o amálgama da garantia de amor e reconhecimento. Em oposição, as crianças percebem que o que queremos lhes transmitir, o nosso saber, parte de uma posição ideal: "(...) nos endereçamos a nossas crianças, dizendo a elas 'façam isso, não façam aquilo', ouvem muito bem que 
é primeiramente a nós mesmos que estamos falando isso" (Jerusalinsky et al., 1994, p. 33).

Entre os muitos paradoxos que existem no ato educativo dos filhos, a primeira contradição - e que se torna necessária para bem educar - é um contato de quem educa com a própria infância, muito embora ela nos seja acessível apenas imaginariamente.

\section{"SEI QUE TUDO GIRA EM TORNO DA MAMÃE"}

A partir do século XVIII, a mãe passa a ter um papel fundamental na vida moderna. Em torno principalmente da mãe, centrase a educação dos filhos. As reuniões de pais e mestres nas escolas ainda são um bom indicador desse fato. E é revestida dessa vestimenta social que a mulher encarna a função materna, apoderandose da ilusão de completude com seu bebê.

Após os nove meses de parasitária vida intra-uterina, o bebê humano vem ao mundo enfrentando o mal-estar inicial que se contrapõe a todo conforto: a angústia de pôr os pulmões em atividade, o frio que denuncia a nudez, o contato com a realidade ao avesso da que esteve nos últimos tempos... Foi rompido, com o nascimento, o equilíbrio.

Do nascimento em diante, uma sucessão de fatos acarretará a construção psíquica que tem no reconhecimento do corpo próprio e da noção de exterior o primeiro grande desafio.

Mesmo que precocemente a criança reaja à aproximação e partida das pessoas que cuidam dela, ou até antes disso, quando ainda nos primeiros dias de nascida já se interessava pelo rosto humano, é apenas por volta dos 18 meses que será possível reconhecer-se como sujeito diante de um outro - a mãe. É ela, sem dúvida, a porta de entrada para o sentimento de família.

O trabalho clínico permite que possamos estar em contato com elaborações muito significativas do modo como a subjetividade se organiza e da posição do sujeito em função do seu conjunto de referências.

Recentemente, uma paciente procurou-nos no consultório uma única vez. Aos 16 anos, tentara o suicídio um ano depois de ter perdido o pai. Entrecortava seu discurso com a mesma frase: "Sei que tudo gira em torno da mamãe..." Conta-nos que, quando pequena, a mãe não permitia que ninguém pegasse nela e no irmão: "Fingia que estávamos sujos de cocô..." Narra-nos ainda, que não podia gritar um “a”... O pai não permitia que ninguém chegasse perto da mãe, tampouco dela própria, prometendo matar - na ado- 
lescência, o pai contratava seguranças para acompanhá-la "sem o seu conhecimento". Os pais haviam se separado quando tinha ela 5 anos. Afirmava categoricamente saber muito "o que é certo e o que é errado..." Pretendia "fazer Direito", a faculdade, a mesma em que o pai se formou. Sendo uma "pessoa correta", não tinha namorados, assim como sua mãe, que, segundo ela, não teve namorados nem amantes após a separação (era uma pessoa muito correta também). Atualmente, suas dificuldades estavam em segurar o ciúme que sentia da mãe, ao vê-la receber certos telefonemas que considerava serem um problema. Passou a adotar "rituais de limpeza" que não podiam ser desobedecidos - ao que chamava, em seu diagnóstico, de "uma psicose".

Para analisar apenas alguns aspectos desse fragmento clínico, vejamos: esta paciente não compareceu à sessão seguinte. A relação transferencial necessária à manutenção de um trabalho terapêutico não se estabeleceu. Quem estaria autorizado a intervir nesse processo? Por que não voltou? Continuará ela sustentandose em seus rituais (em que pensa dominar algo, já que a mãe lhe parece estar furtivamente fugindo de seu controle)? Ou a medicação está funcionando como bloqueador para o que a faz sofrer: sustentar o impossível, que é imaginar ser o complemento da mãe.

Como sair do lugar onde "tudo gira em torno da mamãe"?

Uma vez descoberta a sexualidade infantil, Freud teorizou sobre as condições de sujeitamento do bebê humano ao desejo materno. Para que tudo o mais ganhe sentido, será preciso a intervenção de um outro que faça barra, que viabilize a saída da relação dual por uma permissão materna, sem a qual estaríamos entregues ao aprisionamento ("Ninguém podia segurar em mim. Mamãe fingia que estávamos sujos de cocô...”).

\section{A EDUCAÇÃO SE FAZ APESAR DO DESEJO}

No dia 28 de março de 1999, o programa Fantástico, da TV Globo, exibiu a seguinte matéria, que pode ser bastante ilustrativa da inserção de um terceiro na relação entre mãe e filho (no caso exposto a seguir, filha).

Uma jovem, aos 15 anos, toma conhecimento, por intermédio da mãe, da identidade de seu pai, mantida em segredo até então. O pai, um veterinário, casado, pai de outros três filhos, também fica sabendo, junto com a filha, do segredo de tantos anos, até então oculto também para ele. O pai resolve então contratar uma advogada para processar a mãe, por não the permitir exercer a função paterna durante todos os anos em que o sigilo foi mantido. Não viu a filha na infância, não conviveu com seus outros irmãos (filhos dele), e não contribuiu em nada para sua educação. Surge para a finalização da reportagem uma pesquisa de opinião pública, baseada em respostas por telefone, acerca da seguinte pergunta: "A mãe tem o direito de esconder quem é o 
pai?” Após alguns minutos, surge o resultado: $36,4 \%$ dizem que sim, $63,6 \%$ respondem negativamente.

O desejo materno aponta para o de sempre: almejar que a felicidade esteja garantida para ela, mãe, e seu bebê. Em virtude disso, defenderá esta verdade de modo relativo ou absoluto. Esta felicidade será possível na medida em que ela permite à criança vislumbrar algo para além de si mesma. Contrariamente, a felicidade será um projeto impossível, caso a mãe venha a imaginar que constrói para ela e o seu bebê um universo particular, privativo, restritamente especular e dual, do tipo "enfim, sós!" Esta é uma impossibilidade erguida através de habilidosas seduções, que transformam o bebê em falos da mãe.

Quem poderia negar o fascínio mútuo da mãe diante de seu bebê? "A mãe desejaria ser tudo para um filho e que ele, ao mesmo tempo, fosse tudo para ela" (Jerusalinsky et al., 1994, p. 19). É um fascínio que, só depois, apelando ao pai (um "terceiro" ou alguma coisa que tenha materialidade para apoiar a metáfora paterna), poderá ser interditado, pelo lançamento da mãe e bebê na dimensão da falta. É a intervenção paterna que possibilita inseri-los no circuito desejante, fazendo lembrar o que foi "esquecido": é apenas ilusória a completude!

Para a mãe, as marcas cunhadas desde a resolução de seu próprio Édipo estarão em cena fazendo diferença entre exercer plenamente a função materna ou dedicar-se simplesmente às tarefas necessárias de manutenção (maternagem). Ter um filho, permitir a circulação de outras pes- soas nos cuidados com o bebê, autorizar-se a ter outros afazeres além dos cuidados infantis, desejar um outro para ajudá-la a educar uma criança (que não seja apenas um especialista, representante do saber científico), estas são engrenagens de um complexo motor que faz circular o desejo.

No caso exposto pelo programa Fantástico, há uma situação bastante ilustrativa a propósito do que significa a função paterna e de como ela pode operar no sujeito. A jovem de 15 anos não se tornou uma doente psicótica, apesar de não conhecer o pai. Na sua ausência, alguma presença representou para ela a função. Mesmo omitindo a identidade do pai à filha (o que lhe custou um julgamento moral da opinião pública), a mãe não a aprisionou em seu desejo.

\section{APONTANDO SAIIDAS QUE NÃO SEJAM DICAS PARA EDUCAR}

A necessidade atual de encontrar uma resposta acertada para a educação dos filhos é algo tão primordial, que os pais lotam auditórios e consomem vorazmente livros de auto-ajuda - principalmente as mães, que desde cedo se aliam aos pediatras, primeiros especialistas, em busca de um (suposto) saber científico sobre a criança. Talvez isso alimente o narcisismo dos especialistas e os obrigue a fornecer dicas para os pais bem educarem. No entanto, na medida exata em que estes "caem em ten- 
tação" e deixam-se seduzir pelos apelos insistentes, instaura-se a incompetência da família na busca de suas soluções.

A contribuição legítima dos especialistas aos pais talvez seja unicamente a de lembrá-los de que possuem um saber valioso sobre os filhos. $E$ que é justamente este conhecimento o possibilitador de uma variável saudável para o equilíbrio familiar...

Em vez de prescrever receitas de "como viver", pelo alto risco de transformar o conhecimento psicológico em um “saber culinário”, resta a possibilidade de remeter os adultos a pensarem no próprio lugar infante e no percurso adolescente que fizeram, atravessando as negações e idealizações acionadas pela distância no tempo. Assim é, pela travessia da própria educação recebida, que os pais poderão encontrar um acesso para a compreensão das relações que estabelecem hoje com os filhos, sejam eles crianças ou adolescentes.

Quando pensamos na noção de desenvolvimento humano do lugar de um adulto, quase sempre parecemos crer que o objetivo da vida é atingir a maturidade como instância na qual estaríamos livres dos conflitos, atribuídos muitas vezes às instabilidades infantis e adolescentes. Doce ilusão, que os adultos freqüentemente são obrigados a reconhecer! Seria a finalidade da vida a ausência de conflitos? Seria a tão procurada paz a inexistência de todo movimento desejante?

$\mathrm{Na}$ busca de acertar, a família moderna adotou em seu núcleo ideais que guardam relação com os ideais da época atual, e com outros que, desde a Revolução Francesa, fazem parte de nossa concepção sobre felicidade humana - igualdade, fraternidade e liberdade. É a apologia do humanismo!

Ora, a rotina familiar nega muitas vezes esses ideais... E, quando o resultado não coincide com o esperado, um grande sofrimento assola a todos. Os pais notam que erraram, os filhos sentem-se culpados por não merecerem o investimento amoroso e a dedicação recebidas. E se, por um lado, estes princípios humanistas conferiram uma moralidade mais flexível à educação, por outro, fizeram com que negássemos algumas obviedades.

Onde poderá estar a igualdade ao se educar crianças de sexos diferentes, quando uma análise cuidadosa mostra que sexo, posição em relação ao nascimento de irmãos, situação financeira, desejo em relação à gravidez são algumas das muitas coisas que fazem da igualdade do amor aos filhos uma utopia?

Mesmo que as preferências não sejam patentes, no mínimo haverá identificações que tornarão os filhos mais próximos de um, menos afetuosos com o outro, mais agressivos etc. $O$ sexo da criança é a primeira grande diferença que estabelece uma desigualdade de condições na educação; não no sentido de que se eduque modelando para o gênero feminino ou masculino, segundo o critério anatômico, mas que a referência subjetiva e cultural que a sexualidade estabelece, ter ou não ter pênis, já é o bastante para que tenhamos uma posição diversa nas relações em família, desde a preparação, que vai das 
cores das primeiras camisas e fraldinhas até a escolha do nome. Chamarse Júnior ou Neto, receber o nome do pai ou do avô, ter o sobrenome de ambos os pais ou apenas da mãe, tudo isso fará diferença entre irmãos; ou, até, se não houver irmão nenhum (condição que atualmente se torna comum em uma determinada classe social); se é o primeiro filho(a), ou o "caçula" numa família numerosa... Então, não sendo as crianças as mesmas, como poderiam também ser os pais os mesmos?

Onde está a fraternidade se não mergulhada nas incansáveis perguntas: "Sou ou não sou amado (tanto quanto...)?", "De quem você gosta mais?" São indagaçōes que aparecem em episódios familiares banais, de comparações entre o que um irmão ganhou a mais do que outro - mesmo que a disputa seja por mais suco no copo, ou por maior número de batatas fritas no prato.

Onde localizar a liberdade em família, compreendendo que pai e mãe podem agir de modo diferente dos filhos, regidos pelas regras dos adultos?

Vamos imaginar a cena de um pai e uma mãe que idealizaram uma criança e que deparam com uma outra. Diante de si mesmos, é como se não encontrassem a própria face desconhecimento de uma continuidade que o sentimento de paternidade comporta. Diante do filho que não os espelha, não é possível encontrar o elo que os faz lembrar-se de si próprios, dos projetos de evitação dos erros de quando eram filhos...

Entendendo a educação como um projeto que se inicia precocemente, não podemos desprezar a força dos modelos que circulam no ambiente familiar. Embora esses modelos não sejam assimilados tais como uma colagem alienante, não podemos excluir o fato de que é pelas identificações (sempre relacionadas a processos de espelhamento com os membros familiares) que constituímos nossas diferenças, em busca da autonomia.

Quando os pais desejam educar os filhos para o hábito da leitura sistemática, se eles mesmos usufruem da leitura como atividade prazerosa, é mais provável que o filho compreenda de que lugar está falando a pessoa que educa. Tendo os pais encontrado prazer na escolha profissional para além do fato de serem bem remunerados, é menos conflituoso mostrar aos adolescentes que a vocação é uma realização desejante, antes de ser uma busca mercadológica.

Nesse sentido, se há uma dica, é de cá, como especialistas, que observamos algo valoroso em família: a educação para a construção de um posicionamento ético diante da própria família, das pessoas, da cultura em que se vive, das informaçōes nos meios de comunicação, da escola, da religião, enfim, de todas as instituições que fazem parte da vida em sociedade.

Antes de ser uma repetição mecânica de práticas, a educação remete à idéia de costume, de princípios e regras para orientar a ação e a formação de pensamentos problematizadores da realidade. E, como o projeto educativo não é uma proposta solitária, terá êxito se a postura for compartithada pelos que se propõem a executála, lembrando que aquilo efetivamente vivido tem influência decisiva no processo de formação. 


\section{REFERÊNCIAS BIBLIOGRÁFICAS}

Ariés, P. (1981). História social da criança e da fimilia. Rio de Janeiro, RJ: Guanabara.

Cabas, G. (1982). Curso e discurso na obra de J. Lacan. São Paulo, SP: Moraes.

Fernandez, A. (1991). A inteligência aprisionada. Porto Alegre, RS: Artes Médicas.

Jerusalinsky, A.; Melman, C.; Calligaris, C. et al. (1994). Educa-se uma criança? Porto Alegre, RS: Artes e Ofícios.

Kupfer, M. C. (1997). Freud e a educação. São Paulo, SP: Scipione.

Lacan, J. (1987). Os complexos familiares. Rio de Janeiro, RJ: Jorge Zahar.

Laplanche, J. \& Pontalis, J. B. (1986). Vocabulário da psicanálise. São Paulo, SP: Martins Fontes, 1986.

Winnicott, D. W. (1975). O brincar e a realidade. Rio de Janeiro, RJ: Imago.

\section{NOTAS}

1 Em Complexos Familiares, Lacan (1987) ensina que a familia humana é uma instituição. A análise psicológica deve se adaptar a essa estrutura complexa que não pode ser reduzida a um fato biológico, tampouco a um elemento teórico da sociedade.

2 D. W. Winnicott explicita em vários textos seus a vinculação da criatividade ao viver saudável. Em seu livro O brincar e a realidade (1975, p. 95), comenta: "É através da apercepção criativa, mais do que qualquer outra coisa, que o individuo sente que a vida é digna de ser vivida. Em contraste, existe um relacionamento de submissão com a realidade externa, onde o mundo em todos os seus pormenores é reconhecido apenas como algo a que ajustar-se ou a exigir adaptaçāo".
3 Alicia Fernandez utiliza o conceito de enseñante, ao se referir à pessoa que está em aprendizagem em relação ao aprendiente: "Por ensinantes entendo tanto o docente ou a instituição educativa, como o pai, a mãe, o amigo ou quem seja investido pelo aprendente e/ou pela cultura para ensinar" (1991, p. 32).

4 A palavra lei está sendo utilizada em uma acepção psicanalítica. Neste sentido, difere da significação jurídica de regra ditada pela autoridade estatal para manter a ordem numa comunidade, para vincular-se à conotação de estruturador psíquico que instaura proibições e permissões para o sujeito.

5 Enquanto o termo pênis designa o órgão em sua realidade anatômica, o conceito de falo, nos escritos de Freud, sublinha a função simbólica desempenhada pelo pênis. De acordo com Laplanche e Pontalis (1986), o que caracteriza o falo é ser um objeto destacável, transformável e substituível.

Recebido em maio/2001. 